\title{
El desarrollo de la Ciencia Política en ARgentinA
}

\author{
Pablo Alberto Bulcourf \\ pablo_bulcourf@yahoo.com \\ Universidad Nacional de Quilmes (UNQ) \\ Universidad de Buenos Aires (UBA)
}

Este trabajo analiza el desarrollo de la ciencia política en Argentina, teniendo en cuenta los procesos sociales, políticos, culturales y económicos en los que se desenvuelve la disciplina durante el siglo XX. Analíticamente, se da énfasis en los actores, los productos de la actividad científico-académica, las instituciones de docencia e investigación y las redes. El proceso de institucionalización y profesionalización iniciado en los años ochenta, se estudia sobre la base de la conformación de las áreas disciplinarias, entre ellas: la política del Estado, la administración y el público, las instituciones, los procesos políticos y de política comparada, y relaciones internacionales

Palabras clave: Ciencia Política, Argentina, comunidad científica.

\section{The deVelopment of Political Science in ARGENTINA}

This paper analyzes the development of political science in Argentina taking into account the social, political, cultural and economic processes in which the discipline developed during the twentieth century. Analytically, this paper emphasizes actors, scientific-academic products, teaching and research institutions, and networks. The process of institutionalization and professionalization initiated in the eighties is studied based on the conformation of disciplinary areas, including: State, administration and public policy; institutions, political processes and comparative politics, and international relations.

Keywords: Political Science, Argentina, scientific community. 


\section{Pensar la ciencia política Argentina en su dimensión HISTÓRICA ${ }^{1}$}

Este artículo se propone indagar sobre el desarrollo de la ciencia política en Argentina, lo que le confiere un irrenunciable carácter histórico. Esto permite pensar el tiempo en tres dimensiones interconectadas entre sí; por un lado, dar cuenta de la construcción de una comunidad científico-académica productora de una disciplina particular: la ciencia política; esto a su vez queda anclado en una determinada matriz de acontecimientos: un conjunto de factores culturales, económicos y sociales que condicionan, posibilitando o no la creación de este grupo epistémico y dentro de estos aspectos la faceta "política" en el sentido de que la reflexión que realizan los politólogos versa sobre el poder y los poderosos, sobre las luchas y conflictos en torno al Estado, sobre los grupos de interés y los sistemas de creencias y valores que intentan justificar un determinado orden. La presión que el objeto de estudio ejerce sobre la disciplina se hace evidente cuando se restringen las libertades y los regímenes políticos impiden que ellos mismos sean interpelados por el campo intelectual. En la historia particular de la ciencia política en Argentina esto ha sido una constante a lo largo de gran parte del siglo XX.

Por esta razón todas las interrupciones a un ordenamiento democrático han condicionado negativamente la posibilidad de constituir la mencionada comunidad, lo que ha plagado esta historia de marchas y contramarchas, de procesos truncados. Por ellos este artículo parte de la idea de proceso, en el sentido de que el desarrollo de la ciencia política debe ser entendido como el despliegue de determinados elementos que hacen a una idea paulatina de la constitución de un campo científico. Esta concepción no es lineal ni en el tiempo y en el espacio. La ciencia política argentina ha sido extremadamente discontinua por los condicionantes antes mencionados. Por otro lado las características geográficas del país hicieron que las distintas regiones tuvieran historias muy diferentes; e hilando más fino cada institución ha tenido una historia particular y también se han establecido concepciones muy dispares sobre la

\footnotetext{
Se agradece la colaboración y el suministro de datos de: Arturo Fernández, Nélida Archenti, Miguel De Luca, Martín D’Alessandro, Gustavo Dufour, Nelson Cardozo, Gastón Mutti, Anabella Busso, Walter Cueto, Gabriela Catterberg, Jorge Battaglino, Silvia Fontana, Luciano Anzelini, María Elena Martin,Augusto Reina, Lucas Jolias, Sofia Conrero, Cintia Pinillos, Juan Lucca, Melina Guardamagna, Santiago Rotman y Hernán Fair.

Este trabajo forma parte de la agenda del Grupo de Investigación sobre Historia de la Ciencia Política en América Latina de la Asociación Latinoamericana de Ciencia Política (ALACIP).

El autor quiere dedicar este trabajo a la memoria de Guillermo O'Donnell ejemplo para la Ciencia Política.
} 
disciplina. Si algo caracteriza a la ciencia política argentina es su diversidad teórica y metodológica. Desde la restauración democrática iniciada en 1983 los argentinos hemos podido construir un clima de libertad suficiente para que la ciencia política, junto a otros saberes, se pudiera desarrollar.

\section{LOS ESTUDIOS SOBRE LA HISTORIA DE LA CIENCIA POLÍTICA EN ARgentina}

Los estudios sistemáticos sobre la historia de la ciencia política en Argentina son muy recientes; prácticamente no encontramos reflexiones anteriores al proceso democratizador, lo que demuestra tanto el escaso desarrollo de la disciplina como así también la marcada discontinuidad en su desarrollo ${ }^{2}$. Esto se diferencia, por ejemplo, de su hermana la sociología, que desde sus inicios contó con estudios que intentaran dar cuenta de su historia en el país.

Los primeros trabajos fueron pequeños artículos o comentarios que trataron de establecer algunos elementos históricos sobre la ciencia política, entre los que podemos señalar el documento La ciencia política en la Argentina: de la inestabilidad a la transición, realizado por Cleria Guiñazú y María Gutiérrez, difundido durante el Congreso Mundial de Ciencia Política realizado en Buenos Aires en 1991, publicado un año después en la revista Doxa; el trabajo inédito de Marcelo Cavarozzi y Ricardo Martínez Nogueira, Ciencia Política; y el artículo de Luis Aznar y Luis Tonelli La ciencia política en el fin de siglo. Aportes para (re)iniciar una discusión, de 1993.

Desde sus inicios en el año 1996, la revista PostData ha intentado reconstruir la historia de la ciencia política en Argentina a partir de una serie de entrevistas realizadas principalmente a directivos de carreras de grado y posgrado en ciencia política; lo que permitió obtener una mirada tanto global como también regional sobre la disciplina. Para elV Congreso Nacional de Ciencia Política, celebrado en Río Cuarto en 2001, unos jóvenes politólogos y alumnos avanzados de la carrera crearon el periódico Espacios Políticos, en cuyo primer ejemplar apareció el pequeño artículo Haciendo camino ... la intrincada construcción de la ciencia política argentina, escrito por Pablo Bulcourf y Martín D’Alessandro, al que le siguieron una serie de trabajos en el mismo sentido en todos los ejemplares siguientes de la publicación. En el año

\footnotetext{
2 Dos trabajo anteriores a este período que puede enrolarse en una reflexión sobre la ciencia política en la región producidos por argentinos son "La crisis de las ciencias políticas latinoamericanas" de Torcuato Di Tella, y "Ciencia Política y cientificismo" de OscarVarsavsky, ambos de 1971.
} 
2002 aparece uno de los libros colectivos que intentará dar cuenta, en sus diferentes trabajos, del desarrollo disciplinar: Ciencia Política en Argentina. Dos siglos de historia compilado por Arturo Fernández; podríamos afirmar que esta edición actuará como una bisagra en la indagación sobre la ciencia política argentina dada la profundidad de varios de sus capítulos. Durante 2003 aparece el libro Usos de la transición a la democracia. Ensayo, ciencia y política en la década del '80, un detallado estudio sobre los trabajos que trataron de dar cuenta del proceso de democratización en Argentina, elaborado por Cecilia Lesgart, fruto de su tesis doctoral realizada en FLACSOMéxico. Ese mismo año se realiza una nueva edición del Manual de ciencia política compilado por Julio Pinto, en donde se introduce un nuevo capítulo: La ciencia política en la Argentina, escrito por Pablo Bulcourf y Martín D’Alesandro. En 2005 aparece en la Revista de Ciencia Política de la Universidad Católica de Chile, el artículo La ciencia política en la Argentina: el camino de la institucionalización dentro y fuera de las aulas universitarias de Marcelo Leiras, Juan Manuel Abal Medina y Martín D’Alessandro, el cual representa una detallada sistematización de la evolución disciplinar. Dos años después, en la revista Temas y Debates, Cecilia Lesgart publica el artículo Pasado y Presente de la Ciencia Política en la Argentina. Apuntes para un debate sobre su porvenir.

Desde el plano de la investigación institucionalizada, en un primer momento Néstor Legnani y Pablo Bulcourf emprendieron el trabajo El desarrollo de la ciencia política, su práctica profesional y el diseño curricular en la Universidad de Belgrano y, posteriormente, en la Universidad Nacional de Quilmes, Pablo Bulcourf desarrolló las investigaciones La historia de la ciencia política en la Argentina y Los estudios sobre las relaciones cívico-militares en la Argentina (ésta dentro del Programa PIFAS bajo la dirección de Ernesto López). A estas investigaciones le sucedieron El desarrollo de la ciencia política en la Argentina y Brasil en perspectiva comparada, desarrollado también en la UNQ, y La ciencia política en la Argentina y la construcción de su campo disciplinar: un estudio comparado de su desarrollo en las universidades del país, en la Universidad de Buenos Aires.

Los continuos debates y discusiones acerca del campo profesional del politólogo fueron gestando el trabajo La ciencia política como profesión realizado por Juan Cruz Vázquez y Pablo Bulcourf, el que apareció publicado en la revista PostData; siguiéndole Algunas reflexiones sobre la enseñanza de la ciencia política en la Argentina en la misma revista, Almorzando con Gino: Germani y la política en la Argentina en la Revista Argentina de Ciencia Política y Enseñar a comparar: algunos desafíos en la enseñanza de la política comparada en la Argentina en el Boletín de Política Comparada, los tres artículos elaborados por Pablo Bulcourf. Posteriormente Nelson Cardozo y Pablo Bulcourf publicaron los trabajos El desarrollo de los estudios sobre administración y políticas públicas 
en la Argentina a partir del proceso democratizador y Ciencia política y relaciones internacionales en la Universidad Católica de Córdoba: una mirada sobre su desarrollo en las revistas Nuevo Espacio Público y Studia Politcae respectivamente. Por otro lado Juan Lucca realiza una serie de trabajos que reflexionan sobre la situación de la ciencia política, entre los que podemos mencionar: Debates y embates sobre los lindes de la politología y Evaluando la enseñanza politológica en la Argentina contemporánea. Análisis comparativo de 30 carreras universitarias.

En la Universidad Nacional de Cuyo, Melina Guardamagna ha realizado una serie de investigaciones alrededor de la historia particular de la ciencia política en dicha región, realizando los trabajos: La Ciencia Política en Cuyo: el auge antes de la crisis; Elitismo e igualdad política en los orígenes de la Ciencia Política en Cuyo; Los desafíos de la institucionalización: una reflexión en torno al desarrollo de la ciencia política en Argentina; Los estudios internacionales en Cuyo; Los enfoques teóricos en el origen y desarrollo de la ciencia política en Cuyo; La Ciencia Política en Cuyo: el auge antes de la crisis; entre otros. Todos publicados como producto de diversos congresos y jornadas académicas. Esto demuestra el interés que ha comenzado a tener la historia de la ciencia política en varias provincias argentinas.

La indagación específica sobre la evolución de la política comparada en Argentina merece una especial antención. En un primer momento aparece el trabajo de Juan Lucca La política comparada en un mundo globalizado y posteriormente el artículo Las comparaciones no son odiosas. Métodos y estrategias en política comparada de Augusto Reina y Lucas Jolías en la Revista Argentina de Ciencia Política. Recientemente se publica la compilación Tendencias en la producción del conocimiento sobre política comparada en América Latina de Mirta Geary, Juan Lucca y Cintia Pinillos. Cabe destacar que este libro junto a otros trabajos de estos autores forma parte de un conjunto de investigaciones y actividades llevadas a cabo en la carrera de ciencia política de la Universidad Nacional de Rosario, vinculadas a su vez con la Red Latinoamericana de Carreras de Ciencia Política (RELACIP).

En lo que respecta a los estudios comparados sobre la historia de la ciencia política en la región, cabe mencionarse el artículo de Nelson Cardozo Del Centenario al Bicentenario: algunas reflexiones sobre el desarrollo de la ciencia política en los países del Cono Sur, aparecido en la Revista Argentina de Ciencia Política y la ponencia O desenvolvimento da ciência política na Argentina e no Brasil em perspectiva comparada de Pablo Bulcourf y Nelson Cardozo presentada al VII Congreso de la Asociación Brasilera de Ciencia Política (ABCP). Un estudio interesante al respecto lo constituye el trabajo introductorio de David Altman para el número especial de la Revista de Ciencia Po- 
lítica de la Universidad Católica de Chile, el cual fue dedicado a realizar un balance de la disciplina en la región.

En lo que respecta al estudio y balance de la carrera de ciencia política en la UBA la revista Lo que vendrá publica un número especial con varios artículos cortos escritos por los sucesivos directores que fue teniendo la carrera junto a otros trabajos de especialistas en la temática de la historia disciplinar en nuestro medio.

Los congresos nacionales de ciencia política organizados por la Sociedad Argentina de Análisis Político (SAAP) y especialmente las reuniones periódicas de directivos de carreras de ciencia política y relaciones internacionales también se fueron convirtiendo en ámbitos propios para indagar sobre la historia de la disciplina y su profesionalización. Producto de esto surgieron una serie de trabajos compilados por la institución: La Ciencia Política en la Argentina: Base de datos I, La Ciencia Política en la Argentina: Base de datos II y La ciencia política argentina a comienzos del siglo XXI. Durante el X Congreso Nacional de Ciencia Política, realizado en Córdoba en 2011, Arturo Fernández y Cecilia Lesgart organizaron la reunión especial del Research Committee 33, How can we improve our capacity to study politics? De la International Political Science Association (IPSA) donde se presentaron varios trabajos sobre la ciencia política en América Latina.

\section{Algunos elementos Conceptuales para el estudio de LA HISTORIA DE LA CIENCIA POLÍTICA}

La ciencia política es una actividad humana principalmente cognitiva, esto quiere decir que su principal objetivo -y no el único- es la producción de conocimientos sobre cierta porción de "realidad social" que define como "política" y que constituye su objeto de estudio (Bulcourf, 2007). Al ser un quehacer humano es histórico y posee su "propia historia". Al ahondar como práctica "las propias prácticas de las personas" se entrelaza en una doble hermenéutica en donde sujeto y objeto de conocimiento no pueden ser tajantemente separados; situación que comparte con las otras ciencias sociales, y en parte, con toda reflexión humana.

La actividad científica sistemática producida desde la modernidad se encuentra anclada dentro de lo que comúnmente denominamos "comunidad científica", la cual presenta, acorde a cada disciplina y momento histórico, diferentes grados de heterogeneidad $u$ homogeneidad. La diversidad es un rasgo distintivo de toda actividad científica. Esto no debe ser visto como un defecto o retraso en el desenvolvimiento 
de la actividad cognitiva sino algo propio de su acontecer y desarrollo. Por otro lado, en disciplinas que reflexionan sobre el poder, las instituciones y los sistemas de dominación que han implementado los hombres, todo intento de hegemonía cognitiva es perjudicial para comprender la complejidad de la propia política y tiende a callar voces disidentes. En nuestro mundo la ciencia ha pasado a ser la profesión de los científicos, o sea su trabajo, su medio de subsistencia. La aparición de prácticas profesionales propias de este campo con cierto grado de reconocimiento por el resto de la sociedad es una característica de la profesionalización. Es aquí donde podemos hablar del establecimiento de un "campo intelectual" propio de una ciencia ${ }^{3}$.

Como hemos señalado toda comunidad científico-académica se encuentra inserta en una determinada realidad social. Por esta razón es fundamental incorporar estos patrones para su estudio. Muchos expertos han señalado dos dimensiones para este análisis; lo que han denominado la "historia interna", esto significa las características propias del grupo científico y sus quehaceres y peculiaridades; y otra "historia externa" hace referirse a los condicionantes mencionados. Entre ambas dimensiones existe un verdadero "juego dialéctico" ya que también el desarrollo científico condiciona y modifica las prácticas sociales. Por otro lado las particularidades de cada historia nacional, sus clivajes lingüísticos, étnicos y regionales establecen criterios de institucionalización y profesionalización diferenciados dentro de un propio Estadonación.

Para dar cuenta del desarrollo de un campo científico-académico proponemos abordar los siguientes aspectos:

- Los actores, entendidos como las personas y grupos, portadores de su biografía, accionar y valores fundantes. Son agentes sociales en tanto productores y reproductores de sus prácticas con diferentes grados de conciencia y libertad, pero condicionados históricamente. Los actores son constructores de su subjetividad. Estos no sólo actúan en el nivel del "individuo" sino que en la actividad científica se suele hablar también de "comunidades"; es decir los llamados equipos de trabajo o investigación.

- Las instituciones, en tanto ámbitos o espacios en los que se producen y reproducen las prácticas. Las instituciones proveen de marcos de contención, limitación y recursos, como así también la presencia diacrónica de las mencionadas prácticas. La comunidad científica posee sentido e identidad en tanto existan las

3 El concepto de "campo intelectual" ha sido definido por Pierre Bourdieu (2003). 
instituciones y su reproducción. Entre los tipos de instituciones, dependiendo de cómo se va estructurando la comunidad científica en cada país o región, éstas pueden ser de "enseñanza” o de "investigación”, o privilegiar algún rol sobre el otro.

- Los productos, entendidos como los conocimientos que produce y comunica la comunidad científica. Los que se "materializan" en publicaciones, patentes, tecnologías, entre otros. En el campo de las ciencias sociales podemos decir que las publicaciones en revistas científicas, los libros especializados, las comunicaciones y ponencias en congresos y jornadas, los informes de investigación y documentos de trabajo son la expresión acabada de éstos.

- Las redes, entendidas como los lazos interinstitucionales y de vinculación entre la propia comunidad científica y, a veces, con otros ámbitos de la vida social. La cantidad de éstas y su densidad son elementos centrales para analizar los grados de institucionalización de una disciplina. Un ejemplo de ello lo constituyen las asociaciones científicas, verdaderas redes de instituciones y actores.

\section{LOS PERÍODOS EN LA HISTORIA DE LA CIENCIA POLÍTICA EN ARgENTINA}

Uno de los grandes problemas en el estudio de la ciencia política argentina lo constituye el "punto de partida".Ya sabemos que reflexiones sobre los asuntos públicos han existido desde la etapa colonial, acentuándose en el período emancipatorio y en la organización nacional. Las primeras reflexiones de Mariano Moreno y los actores de Mayo; las obras de Esteban Echeverría, Juan Bautista Alberdi y Domingo Faustino Sarmiento entre otros, representan estudios profundos de la realidad política y social nacional orientados principalmente hacia la praxis. Su riqueza analítica y la proyección de sus ideas en el accionar político han permitido la construcción de la matriz ideológica de la construcción del Estado argentino.

Establecer un comienzo contiene un carácter totalmente "arbitrario" en el intento de fechar ese inicio; aunque el estudio comparado de los diferentes desarrollos de la disciplina en otros países nos puede proveer de elementos destacados. Siguiendo los criterios antes señalados hemos decidido comentar nuestro análisis a partir del clima intelectual alrededor del Centenario; donde se hiciera un despliegue inicial de la ciencia política, marcado especialmente por la reflexión en torno al grupo de los llamados liberales reformistas (Zimmermann, 1995), que dio lugar a una serie sosteni- 
da de críticas de época bajo el lema de Gobierno representativo; centrando su estudio sobre las instituciones republicanas, la calidad de las mismas, el rol del federalismo y el problema electoral (Alonso, 2006), todos estos temas vertidos inicialmente en la pluma de autores como Rodolfo Rivarola, José Nicolás Matienzo, Leopoldo Maupas, Mario Bunge, Alfredo Palacios, Juan Chiabra, Raymundo Wilmart, Alejandro Zerboni, Octavio Amadeo, Francisco Rodríguez del Busto, Raúl Orgaz, Rodolfo Moreno, Ernesto Quesada, Manuel Gálvez, Agustín Álvarez, Mario Bravo, Coriolano Albertini y Ricardo Levene, quienes se constituyeron en actores centrales de los debates en torno al tema y lo reflejaron desde las páginas de la Revista Argentina de Ciencias Políticas y otras publicaciones de relevancia.

Junto a la Revista Argentina de Ciencias Políticas, publicada desde 1910 hasta 1928, algunos textos merecen una especial mención, como Del régimen federativo al unitario de Rodolfo Rivarola, Los orígenes de la democracia argentina de Ricardo Levene y principalmente, El gobierno representativo y federal en la República Argentina de José Nicolás Matienzo. Este último reviste un carácter especial ya que se trata de un trabajo de corte institucionalista sobre el régimen político argentino, con un estudio previo de tipo comparado sobre otras naciones. Esta obra se aleja fuertemente del modelo formalista jurídico y propone una metodología de corte positivista acorde con los principales desarrollos de la sociología y la ciencia política norteamericana y europea que Matienzo había adquirido durante su doctorado en Francia.

Desde el ámbito universitario en 1898 se creó la primera cátedra de Sociología en la Facultad de Filosofia y Letras a cargo de Antonio Dellepiane y en 1908 su homónima en la Facultad de Derecho, luego de varios años de enfrentamientos y de la huelga de profesores de 1904, lo que nos demuestra las dificultades de ir institucionalizando los estudios en ciencias sociales. Posteriormente se emularía en Córdoba, introduciéndose en estas primeras décadas gran parte de los debates europeos respecto a las recientes ciencias sociales; que paradójicamente tendrían fin con la Reforma Universitaria. La cercanía de los años treinta marcarían vientos desfavorables para el desarrollo de las ciencias sociales, en 1928 dejará de publicarse la Revista Argentina de Ciencias Políticas, poniendo fin a una tarea continua.

Durante los años 20 y 30 predomina cierta tradición formalista en los estudios políticos. En 1937 se funda el Instituto Argentino de Estudios Políticos y en 1938 la Academia Nacional del Ciencias Morales y Políticas. Entre los estudiosos del derecho político podemos destacar a Horacio Storni y Jorge Tristán Bosch. En la década del 20 se iniciaron en la Universidad Nacional de Litoral los primeros estudios de grado sobre temas políticos e internacionales bajo las licenciaturas en Servicio Consular y 
Servicio Diplomático, cuyo plan es creado en 1921 y comienza a dictarse en 1923, estas actividades se desarrollan en el seno de la Facultad de Ciencias Económicas, Comerciales y Políticas. En 1927 se crean dos doctorados uno en Ciencias Políticas y otro en Diplomacia. A su vez en 1929 las licenciaturas se transforman en las de Ciencias Políticas y otra de Diplomacia, unificándose los planes de estudio en 1954 bajo la denominación de Ciencias Políticas y Diplomacia (Bulcourf y D’Alessandro, 2003). Estas instituciones estuvieron más ligadas a concepciones jurídicas que al debate que entonces se desarrollaba en otras latitudes sobre la ciencia política. Podemos sostener que existe una denominación al título de grado, pero su estructura curricular no correspondía a una propia de la disciplina.

En 1927 se creó en la Facultad de Filosofía y Letras de la Universidad de Buenos Aires el Instituto de Sociología Argentina, el cual tendría solo una etiqueta formal. Durante el final de esta década ya podemos observar que el modelo iniciado por la generación del ochenta se encuentra totalmente agotado produciéndose un quiebre importante en la concepción sobre las ciencias sociales.

El segundo período comienza con el golpe militar de 1930 teniendo como marco de fondo la irrupción del proceso democrático iniciado en 1912, con la sanción e implementación de la Ley Sáenz Peña que establece el voto secreto y obligatorio para los ciudadanos. Esto significa el fin de la matriz ideológica liberal positivista a pesar de los intentos de mantener las prerrogativas políticas y económicas de las élites dominantes de la oligarquía terrateniente. En el plano intelectual encontramos una continua tensión entre un creciente nacionalismo antiliberal y un republicanismo elitista. Dentro de este contexto se crea en 1940 el Instituto de Sociología en la facultad de Filosofia y Letras de la UBA de la mano de Ricardo Levene (h) y de Gino Germani. En esa década la discusión entre una sociología teórica, ligada a la historia del pensamiento y los grandes sistemas de filosofia y de teoría social, y una sociografía, empirista y constructora de datos, de menos valía marcó dos posicionamientos que se verían fuertemente enfrentados décadas más tarde entre el modelo científicoprofesionalista de Germani y los comienzos de la carrera en la universidad porteña vs. una sociología descriptivo-normativa, sin demasiada rigurosidad metodológica y poco anclada en los debates de la sociología internacional de entonces; tendencia representada principalmente por Alfredo Poviña y sus seguidores en Córdoba.

La relación entre algunos intelectuales y el régimen peronista generó una discontinuidad en este proceso que se retomaría con la derrota del gobierno constitucional de Juan Domingo Perón. En el año 1947 Levene y Germani renuncian al Instituto, volviendo este último recién a fines de 1951. Sin embargo, durante los años del pero- 
nismo la discusión en torno al Estado adquirió un rol central, debiéndose resaltar los trabajos de Arturo Enrique Sampay, quien publicará Crítica al Estado liberal burgués y su voluminosa y detallada Teoría del Estado. Haciendo eco de la reciente Constitución la Universidad Nacional de Cuyo crea el Instituto de Ciencia Política y la publicación de su Boletín; esta reforma obligaba a los estudiantes universitarios a cumplir una serie de cursos de índole política.A partir de este antecedente se creó en 1952 en esta Casa de Altos Estudios la carrera de Ciencia Política y Administración Pública con una clara orientación hacia la formación de los cuerpos burocráticos del Estado. Sobresale en este contexto el trabajo del constitucionalista Dardo Pérez Gilhou, quien sería su primer director; iniciándose simultáneamente una fuerte tradición en el estudio del pensamiento político latinoamericano de la mano de Carlos Zuleta Álvarez.

Con la ruptura institucional producida tras el golpe militar al gobierno peronista en 1955 se inicia el tercer período caracterizado por una estructuración bimodal y antagónica del campo político argentino donde la vuelta a las instituciones republicanas adolecerá de una falla democrática sustantiva ya que se proscribirá a la fuerza política mayoritaria. Uno de los hitos más importantes en el desarrollo de las ciencias sociales argentinas sucederá en 1957 con la creación en la UBA, de las carreras de Sociología y de Psicología. La primera, dirigida por Gino Germani, permitiría la construcción de una verdadera comunidad científica orientada hacia la investigación, con un despliegue editorial y de intercambio académico internacional como nunca se había desarrollado en Argentina, construyendo un modelo de sociólogo profesional ligado al quehacer académico. Gino Germani cumplía tanto los roles de liderazgo académico, administrador institucional y también de generador de recursos económicos buscando financiación principalmente de fundaciones extranjeras; su rol de "empresario académico" fue fundamental para la institucionalización de la sociología argentina (Pereyra, 2006).

La “operación Germani” terminó ganando la partida a la visión intelectual comandada por Alfredo Poviña desde el Instituto de Sociología de la Universidad Nacional de Córdoba. Pero la paulatina "politización extremista" y el golpe de 1966 desarticuló el modelo universitario y volvió a recrear fuertemente los viejos fantasmas que se habían adueñado de los años treinta.

Durante este período se producirá una verdadera revolución editorial en las ciencias sociales argentinas, la editorial Paidós, y Eudeba en un primer momento, y posteriormente el Centro Editor de América Latina (CEAL), Amorrortu y el Grupo Editor Latinoamericano (GEL) serán puntos de encuentros y puestas en común. 
En 1957 se crea la Asociación Argentina de Ciencia Política (AACP), bajo la presidencia de Segundo Linares Quintana, director de los Institutos de Derecho Público de las Facultades de Derecho tanto de la Universidad de Buenos Aires como de la Universidad Nacional de La Plata. En el plano internacional, la asociación desarrolló una intensa labor afiliándose a la Internacional Political Science Association (IPSA) y participando activamente en sus congresos, lo que fue complementado a nivel regional con la presidencia de Linares Quintana en la Asociación Latinoamericana de Ciencia Política, en el marco de la cual dictó conferencias en el país y en el exterior, realizando a su vez una vasta actividad editorial. En el plano interno se había retomado la publicación de la vieja Revista Argentina de Ciencias Políticas, llegando a sacar cuatro números. El problema de la asociación radicaba en que la ciencia política era vista como una tarea académica desprendida del derecho público, negándole toda posible autonomía profesional (Bulcourf y D’Alessandro, 2003).

Luego de las disputas sobre la educación superior en Argentina, conocida como la división entre "laica o libre", se permitirá la existencia de universidades privadas en el país. Las dos primeras universidades en crearse, a partir de institutos previos, serán las jesuitas Universidad Católica de Córdoba y la porteña Universidad del Salvador, ambas en 1956; estableciendo esta última la carrera de ciencia política entre las primeras que dictara (Bulcourf y Cardozo, 2010a). En 1969, y a partir del inicio de la reforma al Plan de Estudios de la Universidad del Salvador dirigido por Carlos Flo$\mathrm{ria}^{4}$, se construyó el primer diseño curricular articulado de ciencia política con un claro eje en teoría política empírica y una sólida formación metodológica; en cierta forma "equivalente" al modelo que Germani hiciera para la carrera de sociología en la Universidad de Buenos Aires (Bulcourf y Jolias, 2006). Durante esos años la reciente Universidad Nacional de Rosario heredaba los estudios de ciencia política de la Universidad Nacional del Litoral y también iniciaba un plan de actualización curricular relevante. En 1960 la Universidad Católica de Córdoba crea en la Facultad de Derecho y Ciencias Sociales la carrera originaria de Ciencias Políticas, So-

\footnotetext{
4 A partir de su contacto con la ciencia política norteamericana mediante la obtención de una beca de la Fundación Eisenhower, Floria conocerá a Giovanni Sartori quien le facilitará el modelo de reforma curricular que se implementaría en la Universidad de Florencia, el que inspiró junto al de la carrera de ciencia política de la universidad belga de Lovaina, la reforma al Plan de Estudios de la USAL. Esta "revolución académica" organizada desde el grupo liberal católico Criterio concentrará paulatinamente a destacados profesores, quienes se incorporarán a las aulas entre ellos: Rafael Braun, Natalio Botana, Marcelo Montserrat, Félix Peña, Carlos Strasser, Mariano Grondona, Marcos Kaplan, Arturo Fernández y Guillermo O’Donnell. Lamentablemente la politización extremista y los enfrentamientos internos en el seno de la Compañía de Jesús harían expulsar a gran parte de estos docentes.
} 
ciales y Diplomacia, estableciéndose en 1965 la facultad correspondiente (Bulcourf y Cardozo, 2010a y 2010b).

Paulatinamente en el ámbito de la ciencia política internacional se comenzaría a dar reconocimiento a los estudios políticos argentinos, principalmente a la sociología política de Gino Germani, quien se había convertido en uno de los principales referentes de la teoría de la modernización; y a otros investigadores como Torcuato Di Tella y Darío Cantón. En 1969 la Universidad del Salvador lleva a cabo el Primer Encuentro Internacional de Ciencia Política en el que participan destacados politólogos, entre ellos Robert Dahl, quien inspirara el apartado sobre Argentina en los debates y ponencias presentados en el evento. Otros científicos sociales argentinos también comienzan a destacarse en el ámbito de la ciencia política internacional, como Guillermo O’Donnell, Marcos Kaplan, José Nun y Marcelo Cavarozzi.

El tercer período, con sus diferentes etapas, finalizará con el golpe de Estado de 1976, interrumpiendo el régimen democrático constitucional, se instalaba en Argentina el autodenominado "Proceso de Reorganización Nacional", la dictadura militar más cruenta de la historia argentina. El movimiento obrero, los partidos políticos y el campo intelectual van a ser las principales víctimas del terrorismo de Estado instalado desde el gobierno. La mayoría de los académicos y científicos sufrieron persecuciones, torturas, el exilio y la muerte; Argentina incorporaría al léxico internacional el concepto de "desaparecido" en materia de derechos humanos. En la Universidad de Buenos Aires la carrera de sociología pasará al ámbito de la facultad de Derecho, cerrando la inscripción de alumnos al primer año; posteriormente otras carreras de grado similares en la Universidad Católica Argentina y en la Universidad de Belgrano serán cerradas y hasta la fecha no se volvieron a abrir. Sólo en algunos ámbitos privados se mantuvo cierto debate "a escondidas", dando en alguno de los casos refugio a docentes e investigadores que fueron exonerados de las universidades nacionales; cabe destacar a los doctorados en ciencia política y sociología de la Universidad de Belgrano como uno de estos centros.

Este "intermedio" significó el retroceso más grande para el desarrollo de las ciencias sociales en Argentina. Nuestro cuarto período recién se establecerá con el advenimiento de la democracia a partir de 1983 significando la recuperación de las instituciones republicanas y democráticas básicas mediante la instalación del sistema de elecciones libres y periódicas, permitiendo crear el clima básico de libertad necesaria para el desarrollo de la actividad científica. 


\section{LA CIENCIA POLÍTICA RECIENTE: EL PERÍODO DE INSTITUCIONALIZACIÓN DE LA CIENCIA POLÍTICA ARGENTINA}

El cuarto período va a representar el desarrollo ininterrumpido de la actividad politológica hasta nuestros días. A partir de este momento comienzan los paulatinos procesos de institucionalización y profesionalización disciplinar. Se fueron creando carreras de grado y de postgrado en forma creciente y sostenida a lo largo de estos años; entre ellas las de la Universidad de Buenos Aires, que desde entonces concentraría el mayor número de alumnos, docentes y proyectos de investigación reconocidos. Hasta la fecha se registran en Argentina un total de 44 instituciones de grado en materia de estudios políticos, relaciones internacionales y administración pública, tanto en el ámbito público como privado ${ }^{5}$.

El crecimiento en materia editorial va a constituir uno de los logros más importantes de las ciencias sociales. Las universidades darán un nuevo impulso a sus colecciones destacándose inicialmente Eudeba y la Editorial de la Universidad de Belgrano. Posteriormente éste se expandirá hacia El Centro Editor Latinoamericano y al Grupo Editor Latinoamericano (hoy Nuevohacer); se irán incorporando paulatinamente las librerías editoriales Prometeo y HomoSapiens. Las casas locales de Paidós, Siglo XXI y Fondo de Cultura Económica también incorporarán nuevos títulos y más recientemente las editoriales Temas y Lumière harán un aporte importante al campo de las ciencias sociales. Dentro de las nuevas universidades públicas la Editorial de la Universidad Nacional de Quilmes mantendrá un desarrollo sostenido de varias colecciones de libros y la edición de cuatro publicaciones científicas periódicas de ciencias sociales. Paulatinamente se irán institucionalizando las revistas generales de ciencias sociales Sociedad, Estudios Sociales, Revista de Ciencias Sociales y la continuidad de Desarrollo Económico.

En el caso específico de la ciencia política hoy se cuenta con los aportes de: Temas y Debates, Revista Argentina de Ciencia Política, PostData, Studia Politicae, Política y Gestión, Colección, El Debate Político, Miríada, y Nuevo Espacio Público entre otras. En materia de revistas de "divulgación" podemos mencionar La ciudad futura, Archivos del Presente, Punto de Vista y Ágora Internacional.

Uno de los aspectos a destacar en la producción de revistas científicas periódicas es la incorporación de gran parte de las "reglas editoriales" propias de este campo. En

5 Este cálculo incluye carreras de grado con diferentes denominaciones: ciencia política, ciencias políticas, ciencia política y gobierno, gobierno y relaciones internacionales, política y administración pública, ciencia política y administración pública, relaciones internacionales y administración pública. 
forma paulatina gran parte de estas revistas fueron regularizando su periodización y estableciendo criterios de evaluación y referato cada vez más estructurados y serios. Las revistas PostData y Revista SAAP lograron su incorporación al núcleo básico de revistas científicas evaluadas por el Caicyt del CONICET, estando también registradas con máxima evaluación en el sistema Latindex y la primera también en Scielo, Dialnet, Ulrich e IBSS (International Bibliography of The Social Sciences). Este es uno de los indicadores más claros del proceso de institucionalización y construcción de una comunidad científica que ha logrado la ciencia política argentina.

La creación de la Sociedad Argentina de Ciencia Política (SAAP), surgida como contrapartida a la Asociación Argentina de Ciencia Política cuando ésta se negara a aceptar masivamente a los politólogos que venían del exilio, puede señalarse como uno de los hitos más importantes de este período, convirtiéndose en el nodo central de nucleamiento de la red de instituciones ligadas a las ciencia política. Hasta la fecha, la SAAP ha realizado 10 Congresos Nacionales de Ciencia Política en diferentes regiones del país; publicando en un primer momento el Boletín SAAP y actualmente la Revista $S A A P$. Asimismo, y por convenio con la provincia de Río Negro, efectuó una labor de auditoría sobre el Sistema de formación y capacitación política para jóvenes dirigentes, realizando lo mismo con GESTAR en el Programa de Formación de Jóvenes Dirigentes durante 2012. Para el X Congreso Nacional de Ciencia Política, celebrado en julio de 2011, se inscribieron 1718 participantes; han organizado 128 paneles regulares, se presentaron 1041 ponencias, presentándose 33 paneles especiales, y se dictaron 21 conferencias. Paralelamente, se ha dado continuidad a la participación de los estudiantes con 32 paneles con sus respectivas ponencias y se efectuó la presentación de 29 libros junto a paneles especiales de revistas científicas y páginas web ${ }^{6}$. A partir del VI Congreso Nacional realizado en Rosario la SAAP ha publicado las ponencias en libros formato CD y durante VIII y IX Congreso se presentaron las bases de datos de ciencia política La ciencia política en la Argentina: Base de datos I y II, libros en formato CD que recopilan y sistematizan información académica sobre la disciplina en cuya elaboración participaron tres generaciones de politólogos de diferentes instituciones. Una de las actividades que se han venido desarrollando es la realización de convenios para la difusión de revistas científicas durante diferentes eventos. Se han creado premios especiales, y financiado becas para la participación en diferentes eventos y congresos. Actualmente la SAAP cuenta con 1080 socios individuales y 12 socios institucionales. ${ }^{6}$ Datos suministrados por Santiago Rotman quien se encuentra elaborando un Informe Especial al
respecto para la SAAP. 
Sin lugar a dudas la figura más importante de la ciencia política argentina ha sido Guillermo O’Donnell. Desde la publicación en 1972 de Modernización y autoritarismo ha marcado la agenda de problemas tanto en el país como en la región. Le siguieron trabajos como El Estado burocrático-autoritario y, el emprendimiento más destacado de la política comparada sobre democratizaciones, lo que dio lugar al proyecto del Woodrow Wilson Center sobre "transiciones”. Años después la elaboración de su concepto de "democracia delegativa" y sus trabajos sobre la calidad de la democracia siguieron estableciendo la discusión conceptual. Su último libro Democracia, agencia y Estado sintetiza gran parte de una carrera intelectual comprometida tanto con la disciplina como con los principales problemas políticos y sociales de su época.

\section{LA CONSTITUCIÓN DE LAS ÁREAS DISCIPLINARES}

El sostenido desarrollo de la ciencia política en Argentina dará paso a la constitución de áreas de especialización disciplinar reflejadas tanto en la docencia, la investigación y la transferencia de los conocimientos producidos. Es interesante destacar que junto a este proceso se articula otro de construcción de espacios interdisciplinarios en donde los límites tradicionales se desdibujan para dar paso a ámbitos de superposición y complementariedad. Así expertos en sistemas electorales comparten problemas y teorías con abogados constitucionalistas y geógrafos; los dedicados a la comunicación política lo hacen con los cultores de la comunicación social o los dedicados a las políticas públicas con los sociólogos de las organizaciones, los administradores y los abogados administrativistas. Brevemente trataremos de describir algunos de los aspectos de las tres áreas centrales que se han venido desarrollando.

\section{Estado, administración y políticas públicas}

Esta área es uno de los campos más desarrollados dentro de la ciencia política bajo una concepción ampliamente interdisciplinaria desde el proceso democratizador iniciado a comienzos de la década de los noventa (Agoff, 2003; Bulcourf y Cardozo, 2010c). Uno de los aspectos que menciona Oszlak en relación al caso argentino es que hay una desvinculación entre la implementación de las políticas públicas y la investigación en este campo disciplinar. La falta de articulación entre estas instancias ha tenido consecuencias negativas para la consolidación de esta área de estudio (Oszlak, 1997). En nuestro país la administración pública es eminentemente un área de especialización dentro de las ciencias sociales que se realiza con anterioridad a los estudios de grado. El desarrollo de la administración pública como campo interdis- 
ciplinario tiene su origen dentro del posgrado antes que del grado. El nacimiento de carreras de grado con la denominación administración pública, a excepción de la existente en la Universidad Nacional de Cuyo y la corta experiencia en la Universidad del Salvador, es bastante reciente, encontrándose relacionado con la creación de nuevas universidades y a cambios vinculados a las visiones sobre las ciencias sociales y sus campos de aplicación.

Según Andrieu y Asencio el surgimiento de los posgrados con orientación en Políticas Públicas tiene su inicio a partir del año 1985 con la creación de la Maestría en Políticas Públicas del Instituto Torcuato Di Tella (después Universidad Torcuato Di Tella) con el apoyo del Banco Interamericano de Desarrollo (Andrieu y Asencio, 2006). Sin lugar a dudas el hito más relevante en la constitución de la administración pública y creación de programa de posgrados orientados al sector público fue la creación de la maestría en Administración Pública de la Universidad de Buenos Aires. Del relevamiento de la CONEAU y los diversos portales de las universidades, hemos podido rastrear 15 maestrías en administración o gestión públicas que se dictan en universidades. En lo que respecta a carreras de grado encontramos solo 7 casos, muchos de ellos “combinando" en sus denominaciones las palabras "administración pública" y "ciencia política".

El principal referente del área es Oscar Oszlak, quien fue fundador del CEDES junto a Guillermo O’Donnell y Marcelo Cavarozzi. Se desempeñó durante 25 años como director de maestría en Administración Pública de la Universidad de Buenos Aires, en la Facultad de Ciencias Económicas. Entre sus principales obras podemos mencionar: La formación del Estado Argentino; Merecer la ciudad. Los pobres y el derecho al espacio urbano y la compilación de la obra colectiva Teoría de la burocracia estatal, obra en la que aparece un estudio anterior escrito en forma conjunta por Oscar Oszlak y Guillermo O’Donnell: "Estado y políticas estatales en América Latina: hacia una estrategia de investigación”, aparecido originariamente como Documento del Cedes en 1976 y publicado posteriormente como artículo en varias revistas de la especialidad, es la obra argentina más utilizada en los distintos capítulos que integran el libro Estado y Administración Pública. Críticas, enfoques y prácticas en la Argentina actual, compilado por Guillermo Schweinheim en 2009. Este libro colectivo reúne las ponencias más destacadas de los cinco primeros Congresos Argentinos de Administración Pública organizados en forma conjunta por la Asociación Argentina de Estudios de la Administración Pública (AAEAP) y la Asociación de Administradores Gubernamentales. En materia de teoría del Estado, dos trabajos de Guillermo O’Donnell 
son los más utilizados en la disciplina; Apuntes para una teoría del Estado, aparecido originariamente como documento del CEDES y El Estado burocrático autoritario.

Entre algunos de los más influyentes expertos en el área podemos mencionar a Fabián Repetto, autor de Gestión Pública y desarrollo social en los noventa. Las transformaciones de Argentina y Chile. Otros trabajos destacados son La reforma managerialista de Alejandro Estévez quien también compiló Estado, Sociedad y Cultura Democrática en la Reforma del Estado Argentino; e Introducción a la Administración Pública Argentina: Nación, Provincia y Municipios de Horacia Cao, Gustavo Blutman y Alejandro Estévez.

Entre los iniciadores de los estudios sobre la administración pública cabe mencionar a Pedro Andrieu, quien hace más de 40 años constituyó la primera cátedra de "Administración Pública y Empresas Públicas" de la Facultad de Ciencias Económicas de la UBA. En la Facultad de Ciencias Sociales de la Universidad de Buenos Aires no podemos dejar de mencionar a Mabel Thwaites Rey, quien ha escrito las obras: Alas rotas. La política de privatización y quiebre de Aerolíneas Argentinas y La autonomía como búsqueda, el Estado como contradicción; y las compilaciones junto a Andrea López, de Entre tecnócratas globalizados y políticos clientelistas. Derrotero del ajuste neoliberal argentino. Dentro de otros grupos de investigación en administración pública, dentro de la UBA, podemos mencionar el Programa de Estudios sobre Sector Público y Reforma del Estado, dirigido por Dora Orlansky, en el Instituto Gino Germani; y el Centro de Investigaciones en Administración Publica (CIAP) en la Facultad de Ciencias Económicas, dirigido por Isidoro Felcman, ambos sedes de proyectos de investigación UBACYT, que desarrollan actividades de investigación en forma regular desde el año 1994 y 2001, respectivamente.

En la Universidad Nacional de Rosario fue creado en 1997, por docentes de la Facultad de Ciencia Política y Relaciones Internacionales de dicha casa, el Grupo Política y Gestión. Surgido bajo los lineamientos del Programa Universitario de Administración Pública, esta institución se radicó como Centro de Estudios de la Facultad de Ciencia Política y Relaciones Internacionales. Actualmente se encuentra dirigido por Cristina Díaz y sus miembros son docentes e investigadores de esta Facultad con reconocida trayectoria en el campo de la Gestión Pública, particularmente en el ámbito local. Las actividades incluyen la investigación y la participación en múltiples proyectos con organizaciones del ámbito estatal y comunitario, los cuales han permitido desarrollar una valiosa capacidad de trabajo interdisciplinario.

En la Universidad Nacional de Lanús se destaca la figura de Carlos MaríaVilas. Dentro de los estudios sobre desarrollo local podemos situar a Pedro Pírez; Alejandro 
Villar, Sergio Ilari y Daniel Cravacuore, director de la Unidad de Fortalecimiento de los Gobiernos Locales de la Universidad Nacional de Quilmes; y Gustavo Badía, anteriormente en el ICO de la Universidad Nacional de General Sarmiento y a partir de 2010 en la Universidad Nacional de San Martín. En la Universidad Nacional de La Matanza ha venido desarrollando su programa de investigación Gloria Mendicoa con estudios fuertemente anclados en la realidad de ese partido y sus aledaños. En la Universidad Nacional de Córdoba desde hace años se destaca el trabajo de Claudio Tecco orientado también hacia los estudios sobre políticas locales.

Entre la producción realizada en la Universidad Católica de Córdoba relativas a la temática podemos mencionar Diseño y gestión de políticas públicas. Hacia un modelo relacional de Emilio Graglia, Políticas públicas y largo plazo. El programa social mexicano PROGRESA de Marcos Roggero y Sobre llovido mojado de Silvia Fontana. En cuanto a la problemática de la comunicación gubernamental orientada hacia las políticas públicas y las decisiones de gobierno cabe mencionar La construcción del consenso. Gestión de la comunicación gubernamental de Luciano Elizalde, Damián Fernández Pedemonte y Mario Riorda. Entre los egresados de la Universidad Nacional de Cuyo podemos mencionar a los destacados investigadores Aldo Isuani, Eduardo Bustelo y Emilio Tenti Fanfani, quienes a su vez ejercieron importantes cargos en la gestión pública en diferentes gobiernos desde la democratización.

Uno de los campos que ha venido desarrollando en los últimos años es el de las políticas de seguridad pública; temática de alguna forma "abandonada" por la ciencia política desde la democratización y retomada a partir de la denominada "crisis del modelo policial". Este conjunto de problemáticas es fuertemente interdisciplinaria compartiendo espacios con la criminología, el derecho penal, la psicología y la sociología del delito. Dentro de la ciencia política la figura más destacada es Marcelo Sain, quién además de investigar y poseer una importante producción académica ha ocupado varios cargos de gestión en el área. Entre sus principales obras podemos destacar El leviatán azul. Policía y política en la Argentina y La Reforma policial en América Latina. Una mirada crítica desde le progresismo.

Dos trabajos recientes merecen ser mencionados, por un lado Lecturas sobre el Estado y las políticas públicas: Retomando el debate de ayer para fortalecer el actual, compilado por Carlos Acuña, el que sintetiza gran parte de la trayectoria mundial y regional sobre la problemática del Estado y las políticas públicas; y Estado y Administración Pública: Críticas, enfoques y prácticas en la Argentina actual, compilado con Guillermo Schweinheim, obra que reúne las principales ponencias de los Congresos Argentinos de Administración Pública organizados por la AAEAP, principal evento en el 
país específico sobre esta temática. En esta institución cabe mencionarse los aportes sustantivos para su creación y continuidad de Alberto Bonifacio y del ya mencionado Guillermo Schweinheim. Fuera del ámbito universitario, la Dirección de Investigaciones del Instituto Nacional de la Administración Pública realiza y promueve estudios e investigaciones para contribuir al desarrollo del conocimiento sobre la administración pública y el Estado.

\section{Instituciones, procesos políticos y política comparada}

Este espacio es muy amplio y dificil de especificar. Por un lado tenemos que señalar diferentes ámbitos de la práctica profesional del politólogo en los cuales los problemas de su especificidad tienen relevancia. En un primer momento la docencia universitaria concentrará la atención de muchos politólogos. La reconstrucción del espacio universitario es fundamental para la formación de las futuras generaciones y requiere articular la disciplina local con el estado del arte a nivel internacional. Durante la dictadura militar se habría sufrido el deterioro enorme de la enseñanza y su "vuelta" al ámbito del derecho por considerarlo menos nocivo que las ciencias sociales. Esto va acompañado de reformas curriculares importantes. En la enseñanza de las instituciones y procesos políticos se van a destacar varios docentes que se preocuparán por esta actualización curricular. En el entorno metropolitano alrededor de la Universidad del Salvador se van a destacar figuras como las de Emilio Saguir, Eugenio Kvaternik, Julio Pinto, Moscato, Luis Brajterman y Néstor Legnani; muchos de ellos se incorporarán posteriormente a la reciente carrera creada en la Universidad de Buenos Aires. A esta institución se le sumarán varios sociólogos políticos y filósofos, muchos de los cuales se encontraban exiliados en el exterior durante la dictadura; podemos mencionar entre ellos a Atilio Borón, Luis Aznar, Liliana de Riz, Edgardo Catterberg, Mario Dos Santos, Isidoro Cheresky, Emilio de Ipola, Lilia Puig, Daniel García Delgado, Mario Toer, Nélida Archenti, entre otros.

Posteriormente se fueron sumando otros colegas provenientes del exterior, muchos de los cuales ingresaron al CONICET o se radicaron en las nuevas carreras creadas en las recientes universidades del conurbano o en instituciones privadas. Entre ellos podemos mencionar a Carlos Acuña, Marcelo Cavarozzi, Mario Serrafero, Ernesto López, José Nun, e historiadoras como María Matilde Ollier. En la Universidad Nacional de Rosario también se llevará un proceso de reforma curricular con un claustro de profesores fuertemente comprometidos con esta nueva etapa; entre los que podemos mencionar a María de los Angeles Yannuzzi, Arturo Fernández, Hugo Quiroga, Artemio Melo, Mónica Billoni, Cristina Díaz, Osvaldo Iazzetta, Nélida 
Perrona, Adriana Chiroleau, junto a jóvenes egresados que comenzarán su carrera académica en el comienzo de la democracia. En la Universidad Nacional de Cuyo esta nueva etapa tuvo un importante aporte de profesores como Walter Cueto, Julián Bertranau y Amelia Barreda; muy comprometidos con la actualización curricular de contenidos.

Temáticamente podemos sostener que en una primera etapa las preocupaciones se centraron en analizar los procesos de transición democrática en la región; intentando comprender los fuertes cambios entre un régimen autoritario y la nueva democracia. Entre algunas obras podemos mencionar primeramente a Autoritarismo y democracia: 1975-1983 de Marcelo Cavarozzi; Ideología y discurso populista de Emilio de Ipola y Ensayos sobre la transición democrática argentina de José Nun y Juan Carlos Portantiero. Le siguieron otros trabajos como Participación política y pluralismo en la Argentina contemporánea de Ariel Colombo y Vicente Palermo; Estado, capitalismo y democracia en América Latina de Atilio Borón; El capitalismo político tardío y su crisis en América Latina de Marcelo Cavarozzi, y el trabajo sobre partidos políticos Evolución del sistema de partidos políticos en Argentina, Brasil y Perú (1960-1985) de Torcuato Di Tella. Una serie de compilaciones sintetizan los temas y problemas que prevalecieron, entre las cuales podemos mencionar Proceso, crisis y transición democrática de Oscar Oszlak; Ensayos sobre la crisis política argentina de Julio Pinto, y La nueva matriz política argentina de Carlos Acuña.

Posteriormente las reflexiones en torno al menemismo y los cambios estructurales por los que transitó la sociedad argentina fueron centrando la reflexión de muchos estudiosos. Podemos mencionar los trabajos Pilotos de tormentas. Crisis de representación y personalización de la política en Argentina (1989-1993) y Representación y liderazgo en las democracias contemporáneas, ambas de Marcos Novaro; Política y poder en el gobierno de Menem de Vicente Palermo y Marcos Novaro; y la compilación de Ricardo Sidicaro y Jorge Mayer Política y sociedad en los años del menemismo. Otras obras colectivas que merecen ser mencionadas son Las nuevas democracias del Cono Sur: cambios $y$ continuidades de Julio Pinto; $A$ veinte años del golpe: con memoria democrática de César Tcach y Hugo Quiroga; Elementos para el análisis político. La Argentina y el Cono Sur en los '90 de Eugenio Kvaternik, y Algunos desafíos políticos e internacionales de nuestra época de Arturo Fernández y Silvia Gaveglio.

Posteriormente varios trabajos se van a proponer analizar los cambios institucionales, la relación entre los sistemas de partidos y el régimen político y, paulatinamente, el funcionamiento de los sistemas provinciales. Entre algunos trabajos podemos citar 
Democracia ¿Gobierno del pueblo o gobierno de los partidos? de José Nun; Poder y hegemonía de Natalio Botana, y una serie de investigaciones realizadas por Mario Serrafero, destacándose: Momentos institucionales y modelos constitucionales. El poder y su sombra: los vicepresidentes. Exceptocracia. ¿Confín de la democracia? Intervención federal, estado de sitio $y$ decretos de necesidad y urgencia.

Entre los temas especiales se han destacado los trabajos sobre sistemas electorales. Podemos mencionar el trabajo pionero de Gregorio Badeni Comportamiento electoral en la Argentina y la compilación Los sistemas electorales. Sus consecuencias políticas y partidarias de Luis Aznar y Mercedes Boschi. Posteriormente Clase política y reforma electoral de Guillermo Molinelli; y la compilación de Dieter Nohlern y Liliana De Riz Reforma institucional y cambio político.

Los estudios sobre sindicatos y movimiento obrero han ocupado un lugar relevante en la producción de la sociología y la ciencia política argentina, entre algunos de los libros más destacados podemos mencionar Los sindicatos en el gobierno 1973-1976 y El gigante invertebrado, ambos de Juan Carlos Torre. Una de las figuras más destacadas en este tipo de trabajos es la de Arturo Fernández, quien ha tenido una enorme producción editorial, entre algunos de sus libros podemos mencionar a Las prácticas sociales del sindicalismo (1976-1982), Ideologías de los Grupos Dirigentes Sindicales (1966-1973), Las Prácticas Socio-Políticas del Sindicalismo (1955-1985), Sindicalismo e Iglesia, Movimientos Sociales en América Latina, Las nuevas relaciones entre Sindicatos y Partidos, Crisis y decadencia del Sindicalismo Argentino, Flexibilización y crisis del sindicalismo, Empresas y sindicatos frente a la flexibilización laboral, Sindicatos, Crisis y Después, Estado y Relaciones Laborales: transformaciones y perspectivas. También podemos mencionar Política y Relaciones Laborales en la transición democrática argentina, escrito junto a Raúl Bissio, Particularidades Regionales en la tradición sindical argentina, junto a Gloria Rodríguez y Estado, instituciones laborales y ación sindical en países del MERCOSUR frente al contexto de la crisis mundial, en colaboración con Cecilia Senén González. Los trabajos sobre movimientos sociales han atraído a varios politólogos; entre las obras más conocidas podemos mencionar: ¿La lucha es una sola? La movilización social entre la democratización y el neoliberalismo de Sebastián Pereyra y las compilaciones Movilizaciones sociales: ¿Nuevas ciudadanías? Reclamos, derechos, Estado en Argentina, Bolivia y Brasil de Gabriela Delamata, y La Democracia en América Latina. Partidos Políticos y Movimientos Sociales de Arturo Fernández.

Con carácter histórico, muchos politólogos se abocaron a estudiar etapas anteriores a la década del ochenta, principalmente los años sesenta y la etapa de la última dictadura militar. Se destacan los trabajos de Eugenio Kvaternik Crisis sin salvataje: la crisis 
político-militar de 1962-63 (1987) y El péndulo cívico-militar: la caída de Illia; Oposición y gobierno. Los años de Frondizi de Catalina Smulovitz, y La política en suspenso de Liliana de Riz. En lo que respecta al Proceso de Reorganización Nacional podemos mencionar los libros El tiempo del "Proceso". Conflictos y coincidencias entre políticos y militares 1976-1983 de Hugo Quiroga, y Política y dictadura de María de los Ángeles Yannuzzi. Los estudios sobre relaciones cívico-militares tuvieron a Ernesto López y Rut Diamint como referentes; del primero podemos mencionar Seguridad Nacional y sedición militar y Ni la ceniza ni la gloria; y de la segunda, Control civil y Fuerzas Armadas en las nuevas democracias latinoamericanas.

En los últimos años podemos asistir a la producción académica de las nuevas generaciones de politólogos preocupados por el sistema de partidos, los problemas electorales y, cada vez más, por los estudios a nivel subnacional. En gran parte de estos trabajos se destaca una clara sofisticación metodológica, producto en parte de la formación que muchos de estos especialistas recibieron en el exterior mientras realizaban sus respectivos posgrados. Entre estos trabajos podemos mencionar La nueva política de partidos en la Argentina. Crisis política, realineamientos partidarios $y$ reforma electoral de Ernesto Calvo y Marcelo Escolar, y Todos los caballos del rey. La integración de los partidos políticos y el gobierno democrático de la Argentina 1995-2003 de Marcelo Leiras. Entre las obras colectivas se destacan El federalismo electoral argentino compilado por Ernesto Calvo y Juan Manuel Abal Medina, y El asedio a la política. Los partidos latinoamericanos en la era neoliberal de Marcelo Cavarozzi y Juan Manuel Abal Medina. Entre las últimas obras que intentan dar cuenta del proceso iniciado con el gobierno de Néstor Kirchner sobresale el libro La política en tiempos de los Kirchner compilado por Andrés Malamud y Miguel De Luca.

\section{Relaciones internacionales}

El abordaje de los problemas internacionales ha sido central en los estudios políticos argentinos, principalmente a partir de la creación de las carreras de derecho consular y diplomacia en la sede Rosario de la Universidad Nacional del Litoral a comienzos de la década del veinte (Russell, 1985 y Colacrai, 1992). Su objetivo principal fue proveer expertos vinculados al modelo agroexportador y funcionarios preparados para el servicio diplomático. La figura más destacada de esta Casa de Altos Estudios fue Juan Carlos Puig, quien logró no sólo constituir una comunidad académica sino también ocupar importantes cargos de gestión de los asuntos públicos, logrando el grado de canciller de la Nación. Su concepción sobre la "autonomía” en materia de relaciones internacionales constituyó un aporte sustantivo para comprender la par- 
ticularidad de la política internacional desde los países periféricos. Entre sus principales obras podemos mencionar Doctrinas internacionales y autonomía latinoamericana y el libro colectivo De la dependencia a la liberación. Política anterior de América Latina. Entre sus primeros discípulos podemos mencionar a Bruno Bologna, Iris Laredo, Carlos Pérez Llana y Luis Dallanegra Pedraza.

En el año 1963 se crea el Instituto de Servicio Exterior de la Nación (ISEN), en el ámbito de la Cancillería argentina, que se encargará de la formación de los futuros diplomáticos; y en 1978 el Consejo Argentino para las Relaciones Internacionales (CARI) que se encarga principalmente de tareas de difusión, siendo uno de los principales espacios de discusión de los problemas de la política exterior argentina. La primera maestría en relaciones internacionales será creada en 1977 en la Universidad de Belgrano y, recién en 1979, su homónima en el marco de la Sede Buenos Aires de la Facultad Latinoamericana de Ciencias Sociales, considerada durante décadas el principal ámbito de formación de posgrado en el área. Durante este período cabe mencionar los libros Historia de las Relaciones Internacionales Argentinas de Roberto Etchepareborda; El orden internacional y la doctrina del poder y De Chapultepec al Beagle. Política exterior argentina: 1945-1980 de Juan Archivaldo Lanús; y de Gustavo Ferrari, Esquema de la política exterior argentina.

Reinstalada la democracia se fueron construyendo espacios tanto de investigación como de enseñanza de grado y posgrado en relaciones internacionales. El centro más destacado hasta nuestros días es el CERIR, establecido en la ya Universidad Nacional de Rosario a partir de los "herederos intelectuales" de Puig; su creador y director fue Bruno Bologna, quien logró constituir los grupos de investigación y docencia de grado más institucionalizados de Argentina. Estos se encargaron en un primer momento, de impartir las clases de grado en la licenciatura en relaciones internacionales y sostener un conjunto de programas de investigaciones en las diferentes áreas de especialización de este vasto campo y, posteriormente, iniciar los estudios de posgrado en la misma universidad. Entre los principales integrantes del CERIR podemos mencionar a Gladys Lechini, Miryam Colacrai, Anabella Busso, Roberto Miranda, Graciela Zubelzú, Claudia Giaccone, Pedro Romero, Patricia Rojo, Julieta Cortés, Mónica Aparicio, Gustavo Marini, Graciela Bonomelli, Marta Cabeza, Lidia Gatti y María Elena Lorenzini. Una de las producciones más destacadas del centro la constituye la serie de compilaciones alrededor de la política exterior argentina, entre las que podemos mencionar La política Exterior del Gobierno de Menem: Seguimiento y reflexiones al promediar su mandato, La Política Exterior Argentina 1994/1997, La Política Exterior Argentina 1998/2001. El cambio de gobierno. ¿Impacto o irrelevancia?, La Política 
Exterior del Gobierno de Kirchner y La Política Exterior de Cristina Fernández. Apreciaciones promediando su mandato. Entre algunas de las publicaciones de los integrantes del CERIR podemos mencionar: Política Exterior Argentina. Idas y venidas entre 1999 y 2003 y la compilación Política Exterior. Conceptos y Enfoques en torno a la Argentina, ambas de Roberto Miranda; Las relaciones Argentina-Estados Unidos en los noventa. El caso Cóndor II de Anabella Busso, quien también compiló los dos tomos de Fuerzas Profundas e identidad. Reflexiones sobre su impacto en la política exterior. Un recorrido de casos. Por su parte Gladys Lechini publica Las relaciones Argentina - Sudáfrica desde el proceso hasta Menem; y Miryam Colacrai El Ártico y la Antártida. Su rol en las Relaciones Internacionales. Su relevancia desde la perspectiva ambiental. Otros libros relevantes que podemos mencionar son La Argentina y las Repúblicas Post-soviéticas. La vinculación Bilateral con Rusia, Ucrania, Armenia y el caso de Turkmenistán de Graciela Zubelzu, Argentina ante la era del Pacífico. El desafío de competir en Japón de Graciela Bonomelli y Política Exterior, alianzas estratégicas y energía en América Latina. Las relaciones argentinochilenas bajo la lupa, de María Elena Lorenzini.

La Universidad Nacional de La Plata posee dos centros de estudios en el área internacional. El Instituto de Integración Latinoamericana dirigido por Noemí Mellado, el cual lleva a cabo el dictado de la Maestría en Integración Latinoamericana y la publicación de la Revista Aportes para la integración Latinoamericana. El Instituto de Relaciones Internacionales está dirigido por Norberto Consani, donde se publica la revista Relaciones Internacionales. Entre sus miembros más destacados podemos mencionar a Ángel Tello, Alejandro Simonoff, Roberto Miranda y Juan Rial. Entre algunos de los libros más destacados del centro podemos mencionar Apuntes sobre las políticas exteriores argentinas. Los giros copernicanos y sus tendencias profundas y Teorías en movimiento. Los orígenes disciplinares de la política exterior argentina y sus interpretaciones históricas, ambos de Alejandro Simonoff.

En la Universidad del Salvador, además de la licenciatura en relaciones internacionales y algunos posgrados específicos, debemos señalar los aportes de José Paradiso estudiando la Guerra Fría en su libro La era de las superpotencias y su trabajo sobre la historia de la política exterior argentina Debates y trayectoria de la política exterior argentina. En la misma institución también se ha destacado el trabajo de Mirka Seitz quien publica ¿Realismo penitencial o margen de maniobra? Un estudio de las relaciones de Argentina con América Latina y Estados Unidos.

Entre algunas de las publicaciones más reconocidas de las dos últimas décadas podemos mencionar La agenda internacional en los años 90, Enfoques teóricos y metodológicos para el estudio de la política exterior y La política exterior argentina en el nuevo orden mun- 
dial, obras colectivas editadas por Roberto Russell; quien también compila junto a Rubén Perina Las relaciones internacionales de Argentina y, con Roberto Bouzas, Globalización y regionalismo en las relaciones internacionales de Estados Unidos. Mónica Hirst publica Democracia, seguridad e integración: América latina en un mundo en transición. Posteriormente aparece El laberinto argentino: Política internacional en un mundo conflictivo de Mario Rapoport. Juan Tokatlian realiza una serie de estudios especialmente sobre criminalidad compleja y relaciones internacionales, focalizando su estudio en el narcotráfico y el caso "Colombia”, publicando Globalización, narcotráfico y violencia, compilando Drogas y prohibición. Una vieja guerra, un nuevo debate. De este mismo autor podemos mencionar también Hacia una nueva estrategia internacional. Los desafíos de Néstor Kirchner. Otros textos que debemos mencionar son: Reinserción argentina en el mundo, De la Guerra del Golfo al Nuevo Orden y El regreso de la historia: La política internacional durante la posguerra fría, 1989-1997, los tres de Carlos Pérez Llana; Argentina y EE.UU.: Fundamentos de una nueva alianza de Felipe De la Balze y Eduardo Roca y Momentos y Perspectivas. La Argentina en el mundo y en América Latina de Félix Peña.

Las tendencias más recientes en los estudios que involucran la problemática castrense tienden a vincularse con las relaciones internacionales constituyendo el área de la "seguridad internacional". Entre los trabajos pertenecientes a estos enfoques podemos mencionar los trabajos de Rut Diamint, quien edita Argentina y la seguridad y, posteriormente, La Otan y los desafíos en el Mercosur y Democracia y seguridad en América Latina. Agustín Romero publica Las nuevas amenazas a la seguridad. Por otra parte Ernesto López, director del Programa de Investigación sobre Fuerzas Armadas y Sociedad (PIFAS) de la Universidad Nacional de Quilmes compila Escritos sobre terrorismo, un trabajo que incorpora a la problemática de la seguridad internacional la situación posterior al atentado terrorista del 11 de septiembre de 2001 en Nueva York, con un análisis crítico del rol de los Estados Unidos y un detallado estudio sobre el fundamentalismo islámico; a su vez López también compila junto a Marcelo Saín "Nuevas amenazas". Dimensiones y perspectivas. Dilemas y desafíos para la Argentina y el Brasil, una obra compartida entre expertos argentinos y brasileño, sobre los cambios en la seguridad internacional ${ }^{7}$. Entre las instituciones que especialmente se han dedicado al tema merecen ser mencionadas Ser en el 2000 y la Escuela de Defensa 
Nacional, donde se imparten desde hace décadas diferentes cursos y posgrados sobre estas problemáticas.

En los últimos años uno de los temas que también ha concentrado la labor de los investigadores ha sido la problemática de la integración regional, especialmente el proceso de construcción del Mercado Común del Sur (Mercosur) en el marco de la globalización. Los trabajos han sido amplios y enfocados desde ángulos disciplinares muy diversos; el derecho internacional, la economía internacional y otras disciplinas se han congregado a analizar este fenómeno. Mencionamos aquí sólo algunos autores y títulos. Aldo Ferrer publica Hechos y ficciones de la globalización y De Cristóbal Colón a Internet: América Latina y la globalización. Una decisión estratégica 1986-2001, compilando también junto a Helio Jaguaribe, Argentina y Brasil en la globalización ¿Mercosur o ALCA? Roberto Lavagna publica Argentina, Brasil, Mercosur e Iris Laredo compila Estado, mercado y sociedad en el Mercosur. Por su parte René Nicoletti publica Identidad y cultura del Mercosur. Un trabajo colectivo para destacar es la compilación realizada por Jerónimo De Sierra Los rostros del Mercosur. El difícil camino de lo comercial a lo societal. Posteriormente aparecen Mercosur: Integración y crecimiento de Roberto Bouzas y José María Fanelli, El Mercosur y los cambios en el sistema político mundial de Mónica Hirst y Roberto Russell, y Mario Rapoport y Amado Luis Cervo compilan El Cono Sur: Una historia común. Le siguen el trabajo de Roberto Russell y Juan Tokatlian El lugar de Brasil en la política exterior argentina y la compilación de Gloria Mendicoa La institucionalidad del Mercosur.

El investigador más destacado de las últimas décadas en la temática es Carlos Escudé. Durante la década de los noventa éste desarrolla uno de los aportes más importantes en el ámbito de los estudios internacionales dentro de las denominadas "teorías críticas" con la elaboración del "realismo periférico", publicando su libro homónimo en 1992 y años después El realismo de los Estados débiles (Souto Zabaleta 2002). Pero el trabajo más destacado lo constituyen los catorce tomos de la Historia general de las relaciones exteriores de la República Argentina, obra colectiva dirigida por Carlos Escudé y Andrés Cisneros, publicada entre 1998 y 2000. Retomando la capacidad analítica de sus conceptos para interpretar la política exterior de China, publicó recientemente Principios de realismo periférico: vigencia de una teoría argentina ante el ascenso de China. 


\section{La CIENCIA Política y SUS desafíos en ARgentina}

La paulatina institucionalización y ampliación del ámbito universitario y de investigación ha ido produciendo una masa crítica de nuevos politólogos fuertemente preocupados por crear espacios de inserción laboral y desarrollo profesional tanto dentro como por fuera del sistema académico. Este proceso requiere del reconocimiento social de la ciencia política como una profesión, y por lo tanto de la aceptación de que los politólogos poseen un conjunto de conocimientos, competencias y habilidades que son considerados de utilidad y que merecen ser remunerados. En los últimos años los ámbitos legislativos a nivel nacional, provincial y municipal han ido incorporando politólogos como asesores. En la administración pública el número de politólogos ha crecido enormemente, principalmente en las áreas ligadas al diseño e implementación de políticas públicas como la Subsecretaría de Gestión Pública y el Instituto Nacional de la Administración Pública (INAP). En la selección realizada por la Cancillería, tanto para el Servicio Exterior de la Nación, como para otros cargos administrativos y de gestión, el número de politólogos y licenciados en relaciones internacionales se ha elevado. El ámbito de la opinión pública y la consultoría de medios han ido incorporando politólogos en áreas antes reservadas para sociólogos y psicólogos. Organismos internacionales como las Naciones Unidas, el Programa de Naciones Unidas para el Desarrollo, la Organización Mundial para las Migracioes, o la Organización de Estados Iberoamericanos han contratado mayormente a politólogos y licenciados en relaciones internacionales para la realización de tareas de gestión e investigación. El sector empresario ha ido abriendo espacios en las áreas de relaciones institucionales y de alta gerencia para aquellos que se reivindican como politólogos. Muchas universidades han desarrollado en forma conjunta con el Estado nacional y los estados provinciales programas de observación electoral, de análisis de la calidad institucional y la participación ciudadana como el Programa de Auditoría Ciudadana. El crecimiento de Organizaciones No Gubernamentales orientadas hacia el mejoramiento institucional y la producción de conocimiento sobre temas de agenda pública como Poder Ciudadano, Conciencia y especialmente Cippec son claros representantes de este proceso de profesionalización y de reconocimiento por parte de la sociedad (Bulcourf, 2007 y Bulcourf y Vázquez, 2007).

Los cambios mencionados generan un fuerte debate interno dentro de la ciencia política que se va reflejando a la hora de tener que realizar modificaciones en los Planes de Estudio y en la creación de nuevas carreras de grado y posgrados específicos. Anteriormente la disputa se estructuró entre quienes hacían de la ciencia política su actividad central y por lo tanto buscaban su institucionalización y re- 
conocimiento social nacional e internacional de aquellos que solo la visualizaban como un área del derecho público sin autonomía propia. Hoy podemos advertir la existencia de dos grandes ejes de conflictualidad.

El primero, y más relevante, se estructura entre aquellos que ven a la ciencia política como un ámbito de discusión principalmente filosófico, en donde los problemas propios de la disciplina, sus áreas y temáticas no forman parte de su concepción particular de la ciencia política; este sector se opone fuertemente al desenvolvimiento de las cátedras de metodología de la investigación y muchas veces ha propuesto hasta su eliminación. Este grupo también es afin a los que intentando rescatar las viejas cátedras "nacional populares" se oponen al aspecto "científico" de los estudios políticos llegando hasta a proponer la eliminación del término "ciencia" para referirnos a la disciplina. El otro polo está integrado por aquellos que promueven una "autonomía total" de la ciencia política intentando despojarla de toda reflexión más allá de la producción e interpretación del "dato empírico"; este sector tiene una fuerte afinidad con los promotores a ultranza de los modelos econométricos y el extremismo cuantitativista.

El segundo se polariza entre aquellos que ligados a una concepción más tradicional de la disciplina la conciben como una actividad exclusivamente académica ligada a la docencia e investigación auto-reproductiva, donde toda idea de vinculación entre la universidad y otros ámbitos sociales es considerada un desprestigio carente de toda seriedad académica. En contrapartida se encuentran quienes proclaman una profesionalización sin anclaje en la actividad cognitiva y totalmente externa al mundo universitario y al propio origen académico de la ciencia política.

Esto dio lugar a lo que hemos denominado la "colonización" de la ciencia política, ya que esta se transformó en un botín de cultores de la filosofía que, al no encontrar espacio en su propia disciplina, se fueron introduciendo en las jóvenes carreras o en aquellas deterioradas, ocupando espacios curriculares sin el conocimiento propio del campo disciplinar (Bulcourf y Cardozo, 2011c). A esto se le fue sumando la “colonización por dentro" producida por los jóvenes egresados que al ser formados por estos académicos también adolecen de estos conocimientos aunque posean un título de grado de licenciados en ciencia política. Esto se ha intensificado paradójicamente en los últimos años. En una de las carreras más antiguas de nuestro país, por ejemplo, no existe una asignatura introductoria a la disciplina y hay que esperar a llegar al cuarto año para comenzar a estudiar conceptos básicos de ciencia política. En otra de las instituciones más importantes las materias introductorias han sufrido un paulatino corrimiento hacia posiciones claramente anti-ciencia política. En un 
estudio comparado de la evolución diacrónica de los programas de estas materias se puede ver claramente el desplazamiento de autores y temas de la disciplina por otros de corte filosófico; en uno de estos programas la autora más citada en los textos obligatorios es Hanna Arendt.

El otro extremo lo presentan algunos centros privados fuertemente orientados por la ideología y las políticas neoliberales de los años noventa; en ellos el culto ha pasado hacia lo que Gabriel Almond ha llamado, en su trabajo Mesas separadas, la "derecha dura". Se propone un modelo restringido de la ciencia política que apenas combina algunos aportes del neoinstitucionalismo con el rational choice. Metodológicamente se cultivan solamente las técnicas cuantitativas y la utilización de los modelos matemáticos. Prevalece un aire de superioridad frente al resto de la comunidad y sólo se preocupan por su vinculación con algunos sectores de la ciencia política norteamericana.

Tanto la investigación académica como la orientada hacia la toma de decisiones no deben dejar de contemplar el aspecto federal de la organización política argentina. Las dimensiones nacional, provincial y municipal deben estar presentes. Por otra parte la aparición de "nuevas formas" de hacer política, nuevos actores y ejes de conflictualidad deben ser abordados por la ciencia política.

Las ofertas de grado y posgrado deben combinar ejes formativos básicos (de teoría empírica y metodología principalmente) con cierta flexibilidad curricular que les permita a los alumnos adquirir orientaciones y cierta especialización acordes a sus gustos e intereses. La posibilidad de construir un tramo curricular más personalizado debe estructurarse con aspectos formativos que puedan representar actuales y potenciales ámbitos de práctica profesional (por ejemplo, práctica y labor parlamentaria, resolución de conflictos, diseño y evaluación de políticas públicas, entre otros).

Se deben estructurar sistemas de prácticas profesionales y pasantías ya en las carreras de grado con un debido modelo que tienda al compromiso y la acción reflexiva. Deben fomentarse áreas tanto del sector público como del privado. El desarrollo de actividades concebidas como "extra-académicas" por la tradición universitaria no debe ser entendido como un rechazo a la teoría sino todo lo contrario. Es fundamental mantener un fuerte debate teórico con una debida formación metateórica; esto enriquece a la disciplina y permite disponer de espacios de "marginalidad creadora". 
La ciencia política debe mantener un elevado grado de reflexividad interna con un fuerte sentido de autocrítica constante, fomentando la diversidad teórico-metodológica y la constitución de nuevas convergencias orientadas a la redefinición de problemas y estrategias de investigación, dando cuenta de los procesos socio-políticos, su anclaje histórico y la complejidad y diversidad intrínsecas al quehacer humano.

Esperemos que éstos y otros dilemas puedan resolverse permitiendo una mayor institucionalización y profesionalización de una ciencia política que, manteniendo un espíritu crítico, dé cuenta de los principales problemas políticos y sociales tanto de Argentina como de la región en la cual se encuentra inmersa, fomentando un clima de pluralidad y diversidad, contemplando las diferentes cosmovisiones y paradigmas. Este es nuestro desafio.

\section{BibLIOGRAFÍA}

Agoff, Sergio (2003). Algunos problemas acerca de la emergencia del campo disciplinario y la formación en administración pública en Argentina. Trabajo presentado en el Congreso Latinoamericano de Educación Superior en el Siglo XXI.

Almond, Gabriel (1999). Una disciplina segmentada. Escuelas y corrientes en ciencia política. México: Fondo de Cultura Económica.

Alonso, Paula (2006). "Reflexiones y testimonios en torno a la reforma electoral, 1910-1916”. En Darío Roldán (comp.) Crear la democracia. La Revista Argentina de Ciencias Políticas y el debate en torno de la República Verdadera. Buenos Aires: Fondo de Cultura Económica.

Andrieu, Pedro y Miguel Asencio (2006). "Formación gerencial para el Sector Público. Algunas Experiencias". En Andrieu, Pedro y colaboradores Estado y Administración Pública en la Argentina. Buenos Aires: Facultad de Ciencias Económicas UBA.

Blanco, Alejandro (2006). Razón y Modernidad. Gino Germani y la sociología en la Argentina. Buenos Aires: Siglo XXI.

Bourdieu, Pierre (2003). Campo de poder, campo intelectual. Buenos Aires: Guadrata.

Bulcourf, Pablo (2007). "Las nieves del tiempo platearon mi sien: reflexiones sobre la historia de la ciencia política en la Argentina. En Sociedad Global. No 1. Buenos Aires: Universidad Abierta Interamericana.

Bulcourf, Pablo (2008). "Algunas reflexiones sobre la enseñanza de la ciencia política en la Argentina”. En revista POSTData, $\mathrm{N}^{\circ} 13$. 
Bulcourf, Pablo (2008). "Almorzando con Gino: Germani y la política en la Argentina". En Revista Argentina de Ciencia Política. N 10/11. Buenos Aires: Eudeba.

Bulcourf, Pablo y Martín D’Alessandro (2002). "La ciencia política en la Argentina. Desde sus comienzos hasta los años 80". En Revista de Ciencias Sociales, № 13, noviembre, Buenos Aires.

Bulcourf, Pablo y Martín D’Alessandro (2003). "La ciencia política en la Argentina”. En Julio Pinto (comp.): Introducción a la ciencia política, Buenos Aires: Eudeba.

Bulcourf, Pablo y Augusto Reina (2009).“Comprendiendo al Estado:los aportes de Guillermo O’Donnell a su reconceptualización en América Latina”. En Revista de Ciencia Política y Relaciones Internacionales. Universidad de Palermo, Año 2, $\mathrm{N}^{\circ} 2$, noviembre.

Bulcourf, Pablo y Juan Cruz Vázquez (2004). "La ciencia política como profesión”. En POSTData $\mathrm{N}^{\circ} 10$, diciembre, Buenos Aires.

Bulcourf, Pablo y Juan Cruz Vázquez (2007). "La mirada en el espejo: algunas reflexiones sobre el desarrollo de la ciencia política en la Argentina”. En Espacios Políticos, Año 7, $\mathrm{N}^{\circ} 4$, Buenos Aires.

Bulcourf, Pablo y Lucas Jolias (2006). "La historia de la ciencia política en la Universidad del Salvador" EnVV.AA. La ciencia política en la Argentina - 2006. Buenos Aires: Universidad del Salvador.

Bulcourf, Pablo y Nelson Cardozo (2010a). "O desenvolvimento da ciência política na Argentina e no Brasil em perspectiva comparada”. Ponencia AL VII Congreso de la Asociación Brasilera de Ciencia Política (ABCP). Recife, Brasil, agosto.

Bulcourf, Pablo y Nelson Cardozo (2010b). "Ciencia política y relaciones internacionales en la Universidad Católica de Córdoba: una mirada sobre su desarrollo". En revista Studia Politicae, N 18, agosto 2010, Universidad Católica de Córdoba, Córdoba.

Bulcourf, Pablo y Nelson Cardozo (2010c). "El desarrollo de los estudios sobre administración y políticas públicas en la Argentina a partir del proceso democratizador”. Revista Nuevo Espacio Público, № 5, IPAP, Viedma, diciembre.

Bulcourf, Pablo y Nelson Cardozo (2011). "La fábrica de politólogos: la enseñanza de la ciencia política en la Argentina actual”. En revista Espacios Políticos, № 6, Córdoba, julio.

Colacrai de Trevisán, Miryam (1992). "Perspectivas teóricas en la bibliografia de política exterior argentina”. En Russell, Roberto (ed.). Enfoques teóricos y metodológicos para el estudio de la política exterior. Buenos Aires: Grupo Editor Latinoamericano.

De Luca, Miguel (2006). "Ciencia política en Córdoba capital: un balance sobre el VII Congreso Nacional de la SAAP”. En Revista SAAP. Vol. 2, N 3, Buenos Aires. 
Fernández, Arturo (comp.) (2002). La ciencia política en la Argentina. Dos siglos de historia. Buenos Aires: Biebel.

Fernández Ramil, María de los Ángeles (2005). "La ciencia política en el diván: la instrospección disciplinar". En Revista de Investigaciones Políticas y Sociológicas. Vol. 4 N ${ }^{\circ}$ 2, Santiago de Compostela.

García Selgas, Fernando (1994). Teoría social y metateoría hoy. El caso de Anthony Giddens. Madrid: Siglo XXI y Centro de Investigaciones Sociológicas (CIS).

Giddens, Anthony (1987). Las nuevas reglas del método sociológico. Buenos Aires: Amorrortu.

Jolias, Lucas y Augusto Reina (2007). “Una apuesta al desarrollo de la política comparada en Argentina”. En Espacios Políticos, Año 7, N 4, Buenos Aires.

Leiras, Marcelo, Juan Manuel Abal Medina y Martín D’Alessandro (2005). "La ciencia política en la Argentina: el camino de la institucionalización dentro y fuera de las aulas universitarias”. En RCP Revista de Ciencia Política, Vol. 25 N 1, Santiago de Chile.

Lesgart, Cecilia (2003). Usos de la transición a la democracia. Ensayo, ciencia y política en la década del '80. Rosario: HomoSapiens.

Neiburg, Federico y Mariano Plotkin (comp.) (2004). Intelectuales y expertos. La constitución del conocimiento social en la Argentina. Buenos Aires: Paidós.

Olivé, León (1985). Estado, legitimación y crisis. México: Siglo XXI.

Pereyra, Diego (2006). "Los científicos sociales como empresarios académicos. El caso de Gino Germani”. Jornadas de Jóvenes Investigadores en Ciencia Política y Sociología. Universidad Nacional de La Matanza, San Justo.

Roldán, Darío (2006). "La Revista Argentina de Ciencias Políticas. En Darío Roldán (comp.) Crear la democracia. La Revista Argentina de Ciencias Políticas y el debate en torno de la República Verdadera. Buenos Aires: Fondo de Cultura Económica.

Russell, Roberto (1985)."El estudio de las relaciones internacionales en Argentina: dificultades y perspectivas". En Perina, R. M. (comp.). El estudio de las relaciones internacionales en América Latina y el Caribe. Buenos Aires: Grupo Editor Latinoamericano.

Sigal, Silvia (2002). Intelectuales y poder en Argentina. La década del sesenta. Buenos Aires: Siglo XXI.

Souto Zabaleta, Mariana (2002). "La periferia de la teoría y la teoría desde la periferia. Aproximaciones críticas en la teoría de las relaciones internacionales”. En revista POSTData, $\mathrm{N}^{\mathrm{o}} 13$, septiembre.

Varsavsky, Oscar (1971). Ciencia política y cientificismo. Buenos Aires: CEAL. 
Zimmermann, Eduardo (2006). "José Nicolás Matienzo en la Revista Argentina de Ciencias Políticas: los límites del reformismo liberal de comienzos de siglo”. En Darío Roldán (comp.) Crear la democracia. La Revista Argentina de Ciencias Políticas y el debate en torno de la República Verdadera. Buenos Aires: Fondo de Cultura Económica.

Zimmermann, Eduardo (1995). Los liberales reformistas. La cuestión social en la Argentina, 18901916. Buenos Aires: Sudamericana. 